\title{
PENGARUH PEMBERIAN KOMPRES HANGAT TERHADAP PENURUNAN NYERI DISMENORE PADA SISWI KELAS XI SMK MUHAMMADIYAH WATUKELIR SUKOHARJO (THE INFLUENCE OF WARM COMPRESS DECREASE IN DISMENORHEA ELEVENTH GRADE STUDENTS OF SMK MUHAMMADIYAH WATUKELIR SUKOHARJO)
}

\author{
Rima Maratun Nida, Defie Septiana Sari \\ Poltekkes Bhakti Mulia Sukoharjo
}

\begin{abstract}
Warm Compress,Disminorhea. Puberty is a stage of development characterized by the maturity of the sexual organs and achieving the capability to reproduce, in which one of the characteristics of the signs of puberty a woman is the first occurrence of menstruation (menarche). When it happened the first menstruation (menarche) and the next menstruation, a woman will experience abdominal pain (disminorea), when the abdominal pain disorder (disminorea) are not adequately addressed; it can be debilitating to the decrease in performance. Disminorea that occurs continuously in each period, can be one of the symptoms of endometriosis on the reproductive system. One way that can be done to overcome disminorea by performing a warm compress, which is done to meet the needs of a sense of comfort, reduce or relieve pain, reduce or prevent muscle spasms and provide a sense of warmth in the abdomen (stomach). Warm compresses can be done by attaching a rubber bag filled with warm water or a towel that has been soaked in warm water, to the painful body part. The purpose of this study was to determine the effect of a warm compress against dysmenorrhea pain reduction in eleventh student at SMK Muhammadiyah Watukelir Sukoharjo. This type of research is quasi experiment with one group pretest-posttest design with purposive sampling technique sampling number of 30 respondents. Analysis of the data using the Wilcoxon signed-rank test. The results of this study indicated the presence of a warm compress against dysmenorrhea pain reduction in eleventh student at SMK Muhammadiyah Watukelir, with a p-value of 0.000 ( $p<0.05)$.
\end{abstract}

Keywords : Warm Compress,Disminorhea

Abstrak : Kompres Hangat, Nyeri Disminorea. Masa pubertas adalah salah satu tahap perkembangan yang ditandai dengan kematangan organ seksual dan tercapainya kemampuan untuk bereproduksi, dimana salah satu ciri dari tanda pubertas seorang wanita yaitu dengan terjadinya menstruasi pertama (menarche). Ketika terjadi menstruasi pertama (menarche) dan menstruasi berikutnya, seorang wanita akan mengalami nyeri perut (disminore), apabila gangguan nyeri perut (disminore) tidak diatasi dengan baik; maka dapat mengganggu aktifitas sampai dengan penurunan kinerja. Disminorea yang terjadi terus menerus pada setiap menstruasi, dapat menjadi salah satu gejala adanya endometriosis pada sistem reproduksi. Salah satu cara yang bisa dilakukan untuk mengatasi disminore yaitu dengan melakukan kompres hangat, yang dilakukan untuk memenuhi kebutuhan rasa nyaman, mengurangi atau membebaskan nyeri, mengurangi atau mencegah spasme otot dan memberikan rasa hangat pada daerah 
abdomen (perut). Kompres hangat dapat dilakukan dengan menempelkan kantong karet yang diisi air hangat atau handuk yang telah direndam di dalam air hangat, ke bagian tubuh yang nyeri. Tujuan penelitian ini adalah untuk mengetahui pengaruh pemberian kompres hangat terhadap penurunan nyeri dismenore pada siswi kelas XI di SMK Muhammadiyah Watukelir Sukoharjo. Jenis penelitian ini yaitu quasi experiment dengan one group pretest-postest design, dengan teknik sampling purposive sampling sejumlah 30 responden. Analisis data menggunakan wilcoxon signed-rank test. Hasil penelitian ini menunjukkan adanya pengaruh kompres hangat terhadap penurunan nyeri dismenorea pada siswi kelas XI di SMK Muhammadiyah Watukelir, dengan nilai $\mathrm{p}$ sebesar $0,000(p<0,05)$.

Kata Kunci : Kompres Hangat, Nyeri Disminorea

\section{PENDAHULUAN}

Dismenore banyak dialami oleh wanita yang menstruasi, tetapi banyak pula dari mereka yang sering mengabaikan disminorea tanpa melakukan upaya penanganan yang tepat. Kondisi seperti ini bisa saja membahayakan kesehatan wanita apabila dibiarkan tanpa penanganan. Disminore dapat menjadi salah satu gejala endometriosis atau penyakit dismenore sekunder lainnya, oleh karena itu diperlukan upaya penanganan yang tepat dan benar pada wanita yang mengalami disminore terutama usia remajaatau masih dalam masa pubertas. Masa pubertas adalah salah satu tahap perkembangan yang ditandai dengan kematangan organ seksual dan tercapainya kemampuan untuk bereproduksi, dimana salah satu ciri dari tanda pubertas seorang wanita yaitu dengan terjadinya menstruasi pertama (menarche), (Janiwarty dan Pieter, 2013).

Kekakuan atau kejang dibagian bawah perut yang terjadi pada waktu menjelang atau selama menstruasi (disminore), membuat tubuh beristirahat atau berakibat pada menurunnya kinerja dan berkurangnya aktivitas sehari-hari. Gejala dismenore dapat disertai dengan rasa mual, muntah, diare, kram, sakit seperti kolik di perut. Beberapa wanita bahkan sampai mengalami pingsan, keadaan ini muncul cukup hebat sehingga menyebabkan penderita mengalami "kelumpuhan" aktivitas untuk sementara, (Proverawati dan Misaroh, 2009). Salah satu cara yang bisa dilakukan untuk mengatasi disminore (nyeri haid) yaitu dengan melakukan kompres hangat. Kompres hangat dilakukan untuk memenuhi kebutuhan rasa nyaman, mengurangi atau membebaskan nyeri, mengurangi atau mencegah spasme otot dan memberikan rasa hangat pada daerah tertentu (perut), (Uliyah \& Hidayat, 2008). Kompres hangat dapat dilakukan dengan menempelkan kantong karet yang diisi air hangat atau handuk yang telah direndam di dalam air hangat, ke bagian tubuh yang nyeri, dengan diikuti latihan pergerakan atau pemijatan. Dampak fisiologis dari kompres hangat adalah pelunakan jaringan fibrosa, membuat otot tubuh lebih rileks, menurunkan atau menghilangkan rasa nyeri, dan memperlancar aliran darah.

Studi pendahuluan dan wawancara di SMK Muhammadiyah Watukelir kepada 20 siswi, dengan hasil 11 mengalami nyeri saat menstruasi, 2 siswi mengatakan mengurangi nyeri tersebut dengan minum obat anti nyeri dan 6 
mengatakan tiduran di UKS dan diolesi minyak kayu putih, 3 siswi tidak melakukan upaya penanganan, hanya ditahan dan dibiarkan saja. Mereka mengatakan keadaan ini mengganggu konsentrasi belajar di kelas dan membuat malas untuk melakukan aktifitas. Menurut keterangan yang didapat dari guru Bimbingan Konseling, rata-rata siswi yang mengalami dismenore mengeluh sakit perut disertai pusing, lemas dan bahkan ada beberapa siswi yang sampai pingsan ketika benar-benar tidak kuat menahan rasa sakit tersebut, ada pula yang terpaksa tidak bisa masuk sekolah dan izin untuk pulang karena dismenore.

Remaja merupakan periode transisi antara masa anak-anak ke masa dewasa. Di dalam ilmu kedokteran (seperti biologi dan fisiologi), remaja dikenal sebagai suatu tahap perkembangan fisik ketika alat-alat kelamin manusia mencapai kematangan. Hal ini berarti, secara anatomis, alat-alat kelamin maupun organ tubuh yang lain akan memperoleh bentuknya yang sempurna. Masa pematangan fisik berjalan kurang lebih selama dua tahun. Biasanya dihitung mulai haid yang pertama pada wanita dan mimpi basah yang pertama pada pria,(Dahro, 2012).

Mulainya haid pertama (menarche) pada seorang wanita ditandai dengan adanya perdarahan secara periodik, yaitu keluarnya darah dari endometrium yang mengalami nekrosis (sel yang mati). Terjadi sekitar 14 hari setelah ovulasi pada siklus 28 hari. Darah haid sebagian besar berasal dari arteri dan vena (Jannah, 2011). Stadium haid atau menstruasi dibedakan menjadi lima, yaitu: stadium menstruasi (3 -7 hari) dimana sel telur yang tidak dibuahi, luruh bersamaan dengan dinding endometrium sehingga timbul perdarahan; stadium proliferasi (79 hari) dimulai sejak berhentinya darah menstruasi sampai hari ke 14; stadium ovulasi, ditandai dengan sekresi LH (Luteinzing Hormone) yang memacu matangnya sel ovum pada hari ke-14 sesudah menstruasi; stadium sekresi, berlangsung selama 11 hari, dimana terjadi pengeluaran progesteron yang membuat kondisi rahim siap untuk mengadakan implantasi; dan stadium pra menstruasi, terjadi apabila sel telur tidak dibuahi dan berlangsung selama 3 hari, (Kusmiran,2011).

Menstruasi yang normal memiliki siklus tidak kurang dari 24 hari dan tidak melebihi 35 hari, lama haid 3-7 hari dengan jumlah darah selama menstruasi berlangsung tidak melebihi $80 \mathrm{ml}$, ganti pembalut 2-6 kali per hari. Haid normal biasanya 3-5 hari (2-7 hari masih normal), jumlah rata-rata $35 \mathrm{cc}(10-80 \mathrm{cc}$ masih dianggap normal), kira-kira 2-3 kali ganti pembalut per hari (Purwoastuti dan Walyani, 2015).

Gejala-gejala fisik yang umum terjadi selama wanita mengalami menstruasi ialah adanya perubahan berat badan; pembengkakan pada perut, jari, tungkai atau pergelangan kaki, ketidaknyamanan di payudara sebagai akibat pembesaran payudara bila ditekan, akan terasa nyeri dan kaku, sakit kepala, bahkan sebagian wanita mengalami migrain, rasa nyeri dan pegal-pegal pada otot. (Proverawati dan Misaroh, 2009).

Dismenore adalah gangguan aliran darah menstruasi atau nyeri menstruasi, (Proverawati dan Misaroh, 2009). Disminore berdasarkan jenisnya dibedakan menjadi dua, yaitu disminore primer, dimana nyeri menstruasi yang tidak disertai dengan kelainan organ reproduksi; dan disminore sekunder, nyeri 
menstruasi karena adanya kelainan organ reproduksi (endometriosis, fibrods). Pada umumnya disminore terjadi pada perut bagian bawah, kadang menyebar ke sekitarnya, Kadang - kadang disertai mual, muntah, sakit kepala dan diare. Ada beberapa faktor yang menyebabkan terjadinya disminore, antara lain yaitu faktor hormonal, faktor psikis, faktor kejiwaan, faktor resiko.

Menentukan nyeri disminorea, disini menggunakan skala penilaian numerik (Numerical Rating Scale, NRS) yang digunakan sebagai pengganti alat pendeskripsi kata, dengan menggunakan skala $0-10$.

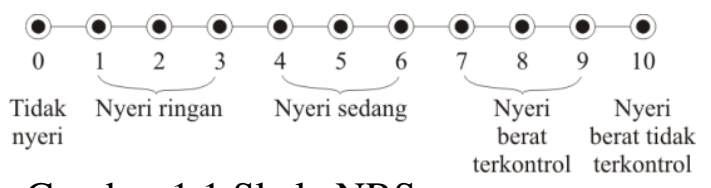

Gambar 1.1 Skala NRS

Pemberian kompres hangat merupakan salah satu tindakan mandiri. Efek hangat dari kompres dapat menyebabkan vasodilatasi pada pembuluh darah yang nantinya akan meningkatkan aliran darah ke jaringan Penyaluran zat asam dan makanan ke sel-sel diperbesar dan pembuangan dari zat-zat diperbaiki yang dapat mengurangi rasa nyeri haid primer yang disebabkan suplai darah ke endometrium kurang, (Natali,2013). Pemberian kompres hangat memakai prinsip pengantaran panas melalui cara konduksi yaitu dengan menempelkan bulibuli panas pada perut sehingga akan terjadi perpindahan panas dari buli-buli panas ke dalam perut, sehingga akan menurunkan nyeri pada wanita dengan dismenore primer, karena pada wanita dengan dismenore ini mengalami kontraksi uterus dan kontraksi otot polos (Anugraheni dan Wahyuningsih, 2013).

\section{METODE PENELITIAN}

Penelitian ini dilakukan pada siswa kelas XI SMK Muhammadiyah Watukelir Sukoharjo pada bulan April - Juni tahun 2016. Jenis penelitian yang digunakan yaitu quasi experiment dengan one group pretest-postest design. Teknik pengambilan sampling yaitu purposive sampling, dengan jumlah sampling 30 siswi. Teknik analisis data menggunakan wilcoxon signed-rank test yang sebelumnya dilakukan uji normalitas data menggunakan uji One-Sample Kolmogorof-Sminrov Test

\section{HASIL PENELITIAN}

1. AnalisaUnivariat

AnalisaUnivariat digunakan untuk menggambarkan karakteristik reponden

a. Tingkat Nyeri Sebelum Diberikan Kompres Hangat pada 30 siswi

Tabel 1

Skor NRS (Numerical Rating Scale) Pratindakan

\begin{tabular}{|c|c|c|c|c|}
\hline No & $\begin{array}{c}\text { Skor NRS } \\
\text { Kategori }\end{array}$ & $\mathbf{F}$ & $\%$ & Keterangan \\
\hline 1 & 1 & 0 & 0 & $\begin{array}{l}\text { Tidak Nyeri } \\
\text { Nyeri }\end{array}$ \\
\hline 2 & 2 & 3 & 10 & $\begin{array}{l}\text { Ringan } \\
\text { Nyeri }\end{array}$ \\
\hline 3 & 3 & 18 & 60 & Sedang \\
\hline 4 & 4 & 8 & 26.7 & $\begin{array}{l}\text { Nyeri Berat } \\
\text { Tak }\end{array}$ \\
\hline 5 & 5 & 1 & 3.3 & Tertahankan \\
\hline & Jumlah & 30 & 100 & \\
\hline
\end{tabular}

b. Tingkat Nyeri Setelah Diberikan Kompres Hangat.berdasarkan skor NRS (numerical rating scale) Tindakan I, II, III 
Tabel 2

Skor NRS (Numerical Rating Scale) Tindakan I

\begin{tabular}{ccccl}
\hline No & $\begin{array}{c}\text { Skor NRS } \\
\text { Kategori }\end{array}$ & F & \% & Keterangan \\
\hline 1. & 1 & 0 & 0 & $\begin{array}{l}\text { Tidak Nyeri } \\
\text { Nyeri }\end{array}$ \\
2. & 2 & 3 & 10 & $\begin{array}{l}\text { Ringan } \\
\text { Nyeri }\end{array}$ \\
3. & 3 & 18 & 60 & $\begin{array}{l}\text { Sedang } \\
\text { Nyeri Berat } \\
\text { Tak } \\
\text { Tertahankan }\end{array}$ \\
5. & 4 & 9 & 30 & 0 \\
\hline
\end{tabular}

Tabel 3

Skor NRS (Numerical Rating Scale)Tindakan II

\begin{tabular}{ccccl}
\hline No & $\begin{array}{c}\text { Skor } \\
\text { NRS } \\
\text { Kategori }\end{array}$ & F & $\%$ & Keterangan \\
\hline 1 & 1 & 1 & 3.3 & Tidak Nyeri \\
2 & 2 & 21 & 70 & Nyeri Ringan \\
3 & 3 & 8 & 26.7 & Nyeri Sedang \\
4 & 4 & 0 & 0 & Nyeri Berat \\
& & & & Tak \\
5 & 5 & 0 & 0 & Tertahankan \\
\hline & Jumlah & 30 & 100 & \\
\hline
\end{tabular}

Tabel 4

Skor NRS (Numerical Rating Scale)Tindakan III

\begin{tabular}{ccccl}
\hline No & $\begin{array}{c}\text { Skor } \\
\text { NRS } \\
\text { Kategori }\end{array}$ & F & $\%$ & Keterangan \\
\hline 1 & 1 & 18 & 60 & Tidak Nyeri \\
2 & 2 & 12 & 40 & Nyeri Ringan \\
3 & 3 & 0 & 0 & Nyeri Sedang \\
4 & 4 & 0 & 0 & Nyeri Berat \\
& & & & Tak \\
5 & 5 & 0 & 0 & Tertahankan \\
\hline & Jumlah & 30 & 100 & \\
\hline
\end{tabular}

2. Analisa Bivariat

Perbedaan skor NRS (Numerical Rating Scale) pratindakan dan Setelah tindakan I, II dan III
Tabel 5

Perbandingan Skor NRS Pratindakan dan sesudah Tindakan

\begin{tabular}{|c|c|c|c|c|c|}
\hline \multirow[b]{2}{*}{ No } & \multirow{2}{*}{$\begin{array}{c}\text { Skor } \\
\text { NRS } \\
\text { Kategori }\end{array}$} & \multicolumn{4}{|c|}{ Skor NRS (Numerical Rating Scale) } \\
\hline & & $\begin{array}{c}\text { Pra- } \\
\text { tindakan }\end{array}$ & $\begin{array}{c}\text { Tindakan } \\
\text { I }\end{array}$ & $\begin{array}{c}\text { Tindakan } \\
\text { II }\end{array}$ & $\begin{array}{c}\text { Tindakan } \\
\text { III }\end{array}$ \\
\hline 1 & 1 & 0 & 0 & 1 & 18 \\
\hline 2 & 2 & 3 & 3 & 21 & 12 \\
\hline 3 & 3 & 18 & 18 & 8 & 0 \\
\hline 4 & 4 & 8 & 9 & 0 & 0 \\
\hline \multirow[t]{2}{*}{5} & 5 & 1 & 0 & 0 & 0 \\
\hline & Jumlah & 30 & 30 & 30 & 30 \\
\hline
\end{tabular}

\section{PEMBAHASAN}

Hasil penelitian ini menunjukkan bahwa siswi yang mengalami nyeri sebelum dilakukanya tindakan kompres hangat sesuai tabel 1.3 : siswi yang mengalami nyeri haid (disminore) paling banyak terdapat dalam kategori 3, yaitu nyeri sedang sebanyak 18 anak $(60 \%)$ dan paling sedikit dalam kategori 5 yaitu nyeri berat tidak tertahankan sebanyak 1 anak (3,3\%) sedangkan untuk kategori 2 yaitu nyeri ringan sebanyak 3 anak $(10 \%)$ dan untuk kategori 4 nyeri berat sebanyak 8 anak $(26,7 \%)$.

Berdasarkan data tersebut diketahui bahwa responden yang mengalami nyeri haid sebelum diberikan kompres hangat sebagian besar berada pada kategori nyeri sedang. Nyeri haid ini dapat disebabkan oleh berbagai faktor, seperti faktor kejiwaan, faktor hormonal, faktor psikis, dan faktor resiko, (Proverawati dan Misaroh, 2009). Faktor psikis dan faktor kejiwaan memegang peran besar dalam timbulnya nyeri haid.

Faktor psikis, seperti tidak stabilnya emosi atau perasaan seorang wanita dapat memicu timbulnya nyeri haid. Faktor kejiwaan, yaitu apabila seorang wanita tidak mendapat pengetahuan menyeluruh tentang haid 
atau menstruasi dapat mengakibatkan adanya disminorea. Faktor hormonal, yaitu meningkatnya hormon progesteron. Serta faktor resiko seperti stress dapat menyebabkan nyeri haid. Secara tidak sadar stress dapat membuat penekanan pada pinggul dan otot-otot punggung bagian bawah. Menurut Proverawati dan Misaroh (2009), orang yang mempunyai kelebihan berat badan dapat mengakibatkan nyeri haid karena di dalam tubuh mereka terdapat jaringan lemak yang banyak, yang mengakibatkan hiperplasi kelenjar reproduksi wanita (terdesak oleh jaringan lemak) sehingga menstruasi terganggu dan timbul nyeri.

Berdasarkan hasil penelitian pada siswi kelas XI di SMK Muhammadiyah Watukelir didapatkan bahwa setelah dilakukan tiga kali tindakan kompres hangat; tindakan kompres hangat yang menunjukkan penurunan nyeri disminore secara signifikan yaitu setelah dilakukan tindakan yang ketiga (tabel 4.3) yaitu kategori tidak nyeri sebanyak 18 anak (60 $\%$ ); nyeri ringan 12 anak (40\%); serta nyeri sedang, nyeri berat, dan nyeri berat tak tertahankan tidak ada (0\%).

Kompres hangat memberikan rasa hangat pada responden dengan menggunakan cairan atau alat yang menimbulkan hangat pada bagian tubuh yang memerlukannya (Natali, 2013). Tujuan dari kompres hangat ini untuk menurunkan intensitas nyeri dengan manfaat pemberian kompres hangat secara biologis yang menyebabkan dilatasi pembuluh darah yang mengakibatkan peningkatan sirkulasi darah.

Pemberian kompres hangat memakai prinsip pengantaran panas melalui cara konduksi dimana panas ditempelkan pada daerah yang sakit untuk melancarkan sirkulasi darah dan menurunkan ketegangan otot sehingga akan menurunkan nyeri pada wanita dengan dismenore primer, karena pada wanita dengan dismenore ini mengalami kontraksi uterus dan kontraksi otot polos (Anugraheni dan Wahyuningsih, 2013).

Berdasarkan hasil uji statistik Wilcoxon Signed Ranks Test pengaruh kompres hangat terhadap penurunan nyeri haid pada siswi kelas XI di SMK Muhammadiyah Watukelir didapatkan nilai signifikasi (p) 0,00 yang berarti bahwa nilai $\mathrm{p}(0,00)$ kurang dari 0,05 ; sehingga dapat disimpulkan bahwa ada pengaruh pemberian kompres hangat terhadap penurunan nyeri dismenorea.

$$
\text { Sejalan dengan penelitian }
$$

(Rohmawati, 2012) tentang perbedaan pemberian kompres hangat dan aromateraphy terhadap penurunan nyeri dismenorea mendapatkan hasil bahwa lebih banyak responden yang diberikan terapi kompres hangat pada daerah abdomen (perut) saat mengalami nyeri menstruasi (dismenore) akan mengalami penurunan rasa nyeri. Pemberian kompres hangat pada perut seorang wanita yang mengalami nyeri haid, dapat meningkatkan relaksasi otot-otot dan mengurangi nyeri akibat spasme atau kekakuan serta memberikan rasa hangat. Rasa hangat dari air ini dapat menyebabkan pembuluh darah meningkatkan aliran darah kebagian tubuh yang mengalami perubahan fungsi, selain itu juga panas dapat mengurangi ketegangan otot menjadi relaks.

Penelitian ini juga sejalan dengan penelitian yang dilakukan oleh Siahaan (2012) tentang penurunan tingkat disminore pada mahasiswi fakultas ilmu keperawatan Universitas Padjajaran dengan menggunakan yoga. Meskipun 
dengan teknik penurunan nyeri haid yang berbeda, tetapi didapatkan hasil yang sama bahwa terjadi penurunan nyeri haid (disminorea) setelah dilakukan tindakan, baik itu kompres hangat atau yoga. Yoga dan kompres hangat, merupakan suatu tindakan yang mempunyai persamaan untuk menurunkan spasme otot yang menekan pembuluh darah dan mengurangi aliran darah. Yoga merupakan salah satu teknik relaksasi yang dapat menurunkan nyeri dengan cara merelaksasikan otot otot yang mengalami spasme (kekakuan) yaitu dengan melatih otot - otot skeleton. Sedangkan pada kompres hangat, memakai prinsip penghantaran panas secara induksi dengan menempelkan buli - buli berisi air panas pada daerah yang nyeri.

\section{KESIMPULAN DAN SARAN}

Ada pengaruh kompres hangat terhadap penurunan nyeri dismenore pada siswa kelas XI di SMK Muhammadiyah Watukelir.

\section{DAFTAR RUJUKAN}

Anugraheni, V dan Wahyuningsih,A. 2013.Efektifitas kompres hangat dalam menurunkan intensitas nyeri dysmenorrhoea. Kediri:Jurnal STIKES Baptis Volume 6, No. 1, Juli 2013.

Dahro,A. 2012. Buku Psikologi Kebidanan : Analisis Perilaku Wanita Untuk Kesehatan. Jakarta: Salemba Medika.

Janiwarty, B dan Pieter, H.Z. 2013. Pendidikan Psikologi untuk Bidan
Suatu Teori dan Terapanya, Yogyakarta: Rapha Publishing

Jannah,N. 2011. Asuhan Kebidanan Ibu Nifas. Yogyakarta: Ar-Ruzz Media.

Kusmiran, E. 2011.Kesehatan Reproduksi dan Wanita. Jakarta: Salemba Medika.

Proverawati, A dan Misaroh,S. 2009. Menarche Menstruasi Pertama Penuh Makna.Yogyakarta: Nuha Medika.

Purwoastuti, E dan Walyani, E.S. 2015.Ilmu Obstetri dan Ginekologi Sosial Bagi Kebidanan. Yogyakarta: Pustaka Baru Press.

Rohmawati,S dan Ekawati,H. 2012. Perbedaan Pemberian Kompres Hangat Dan Aromatherapy Terhadap Penurunan Nyeri Menstruasi (Disminore)Pada Siswi Kelas XI SMA Negeri 1 Karangbinangun http://www.stikesmuhla.ac.id. diakses tanggal 22 mei 2016 jam $15.30 \mathrm{WIB}$

Siahaan,dkk. 2012. Penurunan Tingkat Disminore Pada Mahasiswi Fakultas Ilmu Keperawatan UNPAD Dengan Menggunakan Yoga

http://www.jurnal.unpad.ac.id. diakses tanggal 22 mei 2016 jam 15.45 WIB

Uliyah, $\mathrm{M}$ dan Hidayat, A. 2009.Praktikum Klinik: Aplikasi Dasar-Dasar Praktik Kebidanan. Jakarta: Salemba Medika 